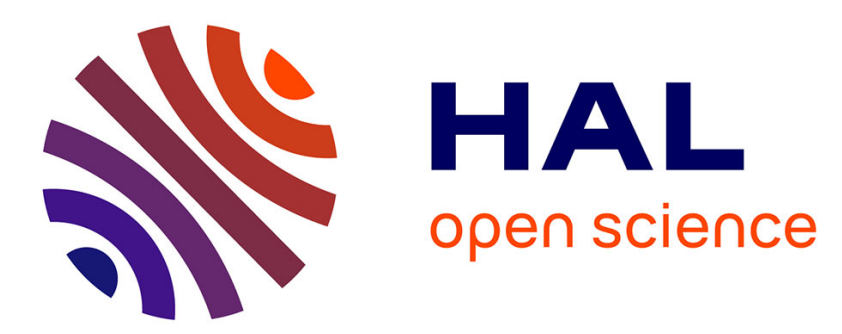

\title{
'How Many of Us Are There?': Group Size Uncertainty and Social Value Orientations in Common Resource Dilemmas
}

\author{
Erik W. de Kwaadsteniet, Eric van Dijk, Arjaan Wit, David de Cremer
}

\section{- To cite this version:}

Erik W. de Kwaadsteniet, Eric van Dijk, Arjaan Wit, David de Cremer. 'How Many of Us Are There?': Group Size Uncertainty and Social Value Orientations in Common Resource Dilemmas. Group Processes and Intergroup Relations, 2008, 11 (3), pp.387-399. 10.1177/1368430208090649 . hal-00571694

\section{HAL Id: hal-00571694 \\ https://hal.science/hal-00571694}

Submitted on 1 Mar 2011

HAL is a multi-disciplinary open access archive for the deposit and dissemination of scientific research documents, whether they are published or not. The documents may come from teaching and research institutions in France or abroad, or from public or private research centers.
L'archive ouverte pluridisciplinaire HAL, est destinée au dépôt et à la diffusion de documents scientifiques de niveau recherche, publiés ou non, émanant des établissements d'enseignement et de recherche français ou étrangers, des laboratoires publics ou privés. 


\title{
'How Many of Us Are There?': Group Size Uncertainty and Social Value Orientations in Common Resource Dilemmas
}

\author{
Erik W. de Kwaadsteniet, Eric van Dijk and Arjaan Wit \\ Leiden University \\ David De Gremer \\ Tilburg University
}

\begin{abstract}
In two studies, we investigate the effects of group size (un)certainty and social value orientations in common resource dilemmas. By focusing on this largely unexplored type of environmental uncertainty, we show that, in contrast to the often replicated finding that resource size uncertainty leads to over-harvesting in common resource dilemmas, group size uncertainty is not necessarily detrimental to the collective interest. Furthermore, we argue and show that whereas under group size certainty people base their individual harvests on the equal division rule, under group size uncertainty they base their harvests on their own social value orientations: whereas under group size certainty both proselfs and pro-socials harvest about an equal share of the common resource, under uncertainty prosocials show self-restraint in order to further their group's outcomes.
\end{abstract}

KEYWORDS group size uncertainty, social dilemmas, social value orientations, tacit coordination

Social dilemmas are situations in which people face a conflict between their personal interests (called defection) and the interests of their group (called cooperation). In such dilemmas, people thus have to choose whether to defect or to cooperate. A choice to defect yields the best payoff to individual group members (i.e. in at least one of the possible outcome configurations; Liebrand \& Messick, 1996), whereas all individual group members are better off if all cooperate than if all defect (see Komorita \& Parks, 1995; Kopelman, Weber, \& Messick, 2002, for reviews).
A well-known type of social dilemma is the common resource dilemma (or commons dilemma). In this type of social dilemma, a group of people have access to a limited common resource. A real-life example of such a resource dilemma

\section{$\overline{\text { Author's note }}$}

Address correspondence to Erik W. de

Kwaadsteniet, Department of Social and

Organizational Psychology, Leiden

University, P.O. Box 9555, 2300 RB

Leiden, The Netherlands

[email: KWAADSTENIET@fsw.leidenuniv.nl] 
is the environmental problem of over-fishing. In this resource dilemma, a group of fishermen have access to a natural common resource, namely the fish population. When individual fishermen choose to further their self-interest by catching as much fish as they can, the collective interest is jeopardized because excessive fishing increases the chance of the resource becoming depleted. So whereas individual fishermen may be tempted to overuse the common resource, the collective interest calls for moderate use. Moreover, to further complicate matters, fishermen often do not know how large the fish population is or how many fishermen are fishing from the same pool (Ostrom, 1990; Takigawa \& Messick, 1993).

Many real-life social dilemmas are thus characterized by environmental uncertainty, or uncertainty regarding the characteristics of the task environment of a social dilemma (Messick, Allison, \& Samuelson, 1988). Earlier research has shown that environmental uncertainty can have a large impact on people's choice behavior. For instance, earlier studies have repeatedly shown that uncertainty regarding the size of the resource (i.e. resource size uncertainty) leads to over-harvesting (e.g. Budescu, Rapoport, \& Suleiman, 1990; De Kwaadsteniet, Van Dijk, Wit, \& De Cremer, 2006; Gustafsson, Biel, \& Gärling, 1999; Hine \& Gifford, 1996; see Van Dijk, Wit, Wilke, \& Budescu, 2004, for an overview of the effects of uncertainty). However, until now very little experimental research has been done to investigate other types of environmental uncertainty, such as uncertainty about the number of group members sharing a resource (see Au \& Ngai, 2003, for an exception).

In real life, group sizes are often uncertain. In many social dilemma situations, people do not know precisely how many group members there are. For instance, water consumers often do not know how many people are consuming water in their water district (see Ostrom, 1990; Takigawa \& Messick, 1993, for numerous other real-life examples). Therefore, more experimental research is needed to obtain more insight into this type of environmental uncertainty (Van Dijk et al., 2004). In the present research, we will investigate how group size uncertainty influences choice behavior in common resource dilemmas.

\section{Earlier research on group size uncertainty}

To our knowledge, only one experimental study has been conducted to investigate group size uncertainty in social dilemmas. In an earlier paper in this journal, Au and Ngai (2003) investigated the effects of group size uncertainty in a single choice step-level common resource dilemma under different protocols of play. Each of their participants made only one harvesting decision in a series of successive rounds, either in a pre-specified order (called a sequential protocol) or whenever (s) he decided to do so (called a selfpaced protocol). Overuse of the common resource would destroy its value and none of the harvests would be granted. In the group size certainty condition, participants were told that the group size was five. In the group size uncertainty condition, they were told that their group was equally likely to be any size between three and seven persons. In all conditions, after the first round participants were fully informed about the combined harvests of all the preceding players in the sequence, but in the self-paced protocol participants were also informed about the number of players who had made requests in the previous round.

The authors were primarily interested in effects on total requests, i.e. effects at the collective level. Their analyses showed that collective overuse was less likely to occur under group size uncertainty than under group size certainty. Under group size uncertainty, participants apparently acted as if the group size was large and requested less, to avoid collective overuse. Ancillary analyses showed that in the self-paced protocol of play, group size uncertainty resulted in participants delaying their harvest decision to a later round until they knew the combined harvests of all the preceding players in the sequence, reducing the risk of collective overuse. By contrast, participants who were certain that the group size was five did not wait and were more likely to make a request in the first round. Given 
that they-on average-requested somewhat more than their equal share (i.e. $1 / 5$ th of the common resource) the pool was more likely to be overused under group size certainty than under group size uncertainty. It may be suggested that the self-paced protocol allowed participants to coordinate their actions. Under group size uncertainty, a participant could gain useful information about the number and the (combined) size of others' requests by delaying his or her own harvest decision to a later round. This raises the question as to what will happen if uncertainty about the number and size of others' requests cannot be reduced by strategic timing of one's decisions.

To investigate the effects of group size uncertainty without the possibility of the strategic timing of decisions, the present studies use a simultaneous protocol of play, in which participants will not be informed about the harvests of their fellow group members. By doing so, we can obtain more insight into the inhibiting effects of group size uncertainty on tacit coordination. Moreover, to answer the question as to how people make decisions when the possibility for tacit coordination is limited, we draw on Snyder and Ickes' (1985) framework of strong versus weak situations. On the basis of this conceptual framework, we will argue and demonstrate that under group size uncertainty people base their harvesting decisions on their own social value orientations.

\section{Tacit coordination and group size uncertainty as a weak situation}

In social dilemmas such as the one described above, it is important for people to coordinate their choice behavior efficiently (e.g. Van Dijk \& De Cremer, 2006; Van Dijk \& Wilke, 1996). In resource dilemmas, it is best for people to coordinate their decisions in such a way that the collective resource does not become depleted, which would be detrimental to individual as well as collective interests. However, efficient coordination is hampered when group members do not know what their fellow group members will decide. This uncertainty about the decisions of other group members is called social uncertainty (or strategic uncertainty; Messick et al., 1988). Earlier research has shown that people can often deal with such social uncertainty by means of tacit coordination (Schelling, 1980; Van Dijk \& Wilke, 1996). That is, group members can predict their fellow group members' decisions by using so-called tacit coordination rules (such as the equal division rule; see also Allison \& Messick, 1990). Furthermore, people also use such coordination rules to determine their own choice behavior.

Imagine a resource dilemma with the same payoff structure as the one Au and Ngai used (2003). In this type of dilemma, a group of five people own a collective resource of 500 coins. Each individual group member can request a number of coins from this resource. However, if the total group request exceeds the number of coins available in the collective resource, the resource becomes depleted and no one receives any coins. The five group members cannot communicate with one another and do not know what their fellow group members will decide (i.e. social uncertainty). Research has shown that people tend to solve this social dilemma by using a tacit coordination rule, in this case the equal division rule. In other words, most group members will request an equal share from the collective resource (e.g. Allison \& Messick, 1990), in this case 100 coins. If all group members decide to do so the resource is optimally used and all group members receive 100 coins. Thus, under certainty in a resource dilemma, people can tacitly coordinate their decisions by applying the equal division rule.

In order to apply the equal division rule, however, people need specific and accurate information about the task environment. To calculate an equal share people have to divide the size of the collective resource by the number of group members. In order to do so, they need to know exactly how large the resource is and how many people the group consists of. Thus, when the group size is uncertain it becomes much more difficult for group members to apply the equal division rule. What do people base their decisions on under such group size uncertainty? 
The answer to this question may be found in Snyder and Ickes' framework of weak versus strong situations (1985; see also Roch \& Samuelson, 1997; Van Lange, 1997). Snyder and Ickes distinguish two types of situations. Strong situations are situations that provide salient cues for people to base their decisions on. In strong situations, people base their decisions on these salient environmental cues. As a result, strong situations lead to little interpersonal variation in their decisions. Weak situations, by contrast, do not provide people with such salient environmental cues. In weak situations, people cannot use external cues to base their decisions on, but they base their decisions on their own dispositional preferences.

When we apply this framework to group size (un)certainty in social dilemmas, we can characterize social dilemmas with group size certainty as strong situations. After all, under group size certainty most people may decide to base their choice behavior on the equal division rule. By contrast, social dilemmas with group size uncertainty can be characterized as weak situations that do not provide people with the salient cues to apply the equal division rule. Under group size uncertainty we can therefore expect people to base their decisions on their own dispositional preference for either cooperation or non-cooperation, i.e. their social value orientation.

Social value orientation (SVO) is a personality variable that indicates how people evaluate outcomes for themselves and others (Messick \& McClintock, 1968; Van Lange \& Liebrand, 1991). Generally, a distinction is made between three types of SVOs (e.g. Van Lange, 1999): (a) cooperation, i.e. the preference to maximize joint outcomes and establish an equal distribution, (b) individualism, i.e. the preference to maximize own outcomes, and (c) competition, i.e. the preference to maximize the relative advantage of own outcomes. Cooperators are commonly referred to as prosocials, and individualists and competitors as proselfs. In social dilemmas, prosocials generally show more cooperative behavior than proselfs (e.g. Kramer, McClintock, \& Messick, 1986; Liebrand \& Van Run, 1985).

\section{Study 1}

Based on the above, we predict an interaction between group size uncertainty and SVO on individual requests. Under group size certainty (i.e. a strong situation), we expect that proselfs as well as prosocials will base their harvesting decisions on the equal division rule and therefore we predict a limited difference between proselfs' and prosocials' individual requests (Hypothesis 1). Under group size uncertainty (i.e. a weak situation), by contrast, we expect that participants will base their decisions on their own SVO, and therefore we predict a (significant) difference between the individual requests of proselfs versus prosocials, i.e. prosocials' requests being lower than those of proselfs (Hypothesis 2).

\section{Method}

Participants and design Participants were 120 students at Leiden University ( 15 men and 105 women, mean age $=20.80$ years) who volunteered for the study. At the beginning of the experiment each participant's SVO was assessed. Group size uncertainty was manipulated as a within-subjects factor. Accordingly, a 2 (SVO: Proselfs vs. Prosocials) $\times 2$ (Group Size Uncertainty: No vs. Yes) factorial design with repeated measures on the latter factor was used.

Procedure The participants were invited to participate in a study on 'group decision making'. Upon arrival at the laboratory they were seated in separate cubicles, each containing a personal computer. This computer was used to give instructions to the participants and to register the dependent measures.

Assessment of SVO At the beginning of the experimental session, participants completed the nine-item version of the decomposed games measure to assess their SVOs (Van Lange, De Bruin, Otten, \& Joireman, 1997). The decomposed games measure has excellent psychometric qualities. It is internally consistent (e.g. Parks, 1994), reliable over substantial time periods (Eisenberger, Kuhlman, \& Cotterell, 
1992), and not related to measures of social desirability (e.g. Platow, 1994). The task consists of nine items, each containing three alternative outcome distributions with points for oneself and an anonymous other. For each of these nine items the participants had to choose which of the three distributions they preferred. Each item contained a prosocial (e.g. self: 500, other: 500), an individualistic (e.g. self: 560, other: 300 ), and a competitive option (e.g. self: 490, other: 90).

Participants were classified as prosocial, individualistic, or competitive when at least six out of nine choices were consistent with one of these three orientations (e.g. Van Lange \& Kuhlman, 1994). Out of 120 participants, 54 $(45 \%)$ were classified as prosocials, $40(33 \%)$ as individualists, and $12(10 \%)$ as competitors. Fourteen participants (12\%) could not be classified and were therefore excluded from further analyses. As in many earlier studies (e.g. Kramer et al., 1986; McClintock \& Liebrand, 1988; Van Lange \& Kuhlman, 1994), individualists and competitors were combined to form one group of proselfs $(n=52 ; 43 \%)$. After completing the SVO measure, participants responded to some filler questionnaires. Next, they were presented with the resource dilemma.

The resource dilemma Participants were informed that they would be part of a group of people, that each group member was sitting in a separate cubicle and that there was no communication possible among participants. Furthermore, participants were not aware of the identity of their fellow group members. Decisions had to be made privately and anonymously.

The participants were presented with two similar resource dilemmas that only differed in the degree of group size uncertainty. Participants learned that at the end of the experimental session a computer would randomly select one of these two situations and that this selected situation would be used to calculate the amount of money each individual group member would earn. Since only the selected situation was used to calculate the participants' earnings, each of these two situations can be considered an independent single-trial resource dilemma.
In each of these resource dilemmas, each group member could request any number of coins from a collective resource of 500 coins. Each coin was worth 0.01 euro ( 1 euro was approximately US\$1.35). For each of these resource dilemmas it held that if the group's collective request would be smaller than or equal to the resource size, the requests were granted and each group member would earn the amount of money he or she had requested in that situation. However, if the group's collective request exceeded the resource size all group members would earn zero outcomes. This resource dilemma is similar to the one used by Au and Ngai (2003) but in the present study participants had to make their decisions simultaneously. Moreover, during and between the two resource dilemmas no feedback was given about the decisions of the other group members nor about the group's collective request.

Manipulation of group size uncertainty The two situations only differed in the degree of uncertainty about the size of the group. Group size uncertainty was manipulated by varying the range of the uniform distribution of the group size. The midpoint of these ranges was kept constant across the two conditions, namely five. Under No Uncertainty, the group size was certain, namely five group members (midpoint $=5$, range $=0$ ). Under Uncertainty, the group would consist of at least two and at most eight group members ( midpoint $=5$, range $=6)$. Participants learned that the exact size of the group in the uncertainty condition would be randomly drawn from these uniform distributions by a computer at the end of the experimental session (i.e. participants were told that their group was equally likely to be any size between two and eight persons). The two conditions were counterbalanced to check for order effects. Preliminary analyses revealed no significant order effects on any of the dependent variables (all $F_{\mathrm{s}}<1$ ).

After the participants had read the instructions of the resource dilemmas, three practice questions were posed to ensure comprehension of these dilemmas. For example, participants were asked how much each group member would earn if the total group request exceeded the size of 
the collective resource; $99 \%$ of all participants answered all three questions correctly. After each question the correct answer was disclosed and the most important characteristics of the dilemmas were repeated. After that, the two dilemmas were presented.

Dependent measures In each of the two (un)certainty conditions, participants requested a number of coins from the common resource. Additionally, under group size uncertainty they were asked to estimate the size of the group. At the end of the experimental session, which lasted about half an hour, all participants were debriefed, thanked, and paid for their participation. In the debriefing, we explained that we would pay all participants the same amount of money for their participation, namely 6 euros (i.e. approximately US\$8), plus the extra money they had earned in one of the two resource dilemmas. All participants agreed with this payment procedure.

\section{Results}

Manipulation check All analyses were performed with 2 (SVO) $\times 2$ (Group Size Uncertainty) analysis of variance (ANOVA) with repeated measures on the latter factor.

In each of the two conditions, we asked participants to indicate how uncertain they were about the size of the group $(1=$ very certain; $7=$ very uncertain) . A $2 \times 2$ ANOVA on this measure only yielded a highly significant main effect of Group Size Uncertainty $(F(1,104)=2417.61$, $\left.p<.0001, \eta^{2}=.96\right)$. As expected, participants were more uncertain about their estimates under Group Size Uncertainty $(M=6.25)$ than under No Group Size Uncertainty $(M=1.10)$. These results show that we were successful in manipulating group size uncertainty.
Individual requests In each of the two conditions, the participants individually requested a number of coins from the common resource (see Table 1). A $2 \times 2$ ANOVA on participants' individual requests yielded a significant main effect of $\operatorname{SVO}\left(F(1,104)=5.07, p<.05, \eta^{2}=.05\right)$, which was qualified by a significant $\mathrm{SVO} \times$ Group Size Uncertainty interaction effect $\left(F(1,104)=6.18, p<.05, \eta^{2}=.06\right)$. It should be noted, however, that in accordance with our expectations, the variance in the Group Size Uncertainty condition was considerably larger than the variance in the No Group Size Uncertainty condition. In order to reduce this heterogeneity of variances, we applied a square root transformation on participants' individual requests in all conditions. After applying this transformation, which successfully reduced the heterogeneity of variances, a $2 \times 2$ ANOVA still yielded a significant main effect of SVO $\left(F(1,104)=4.93, p<.05, \eta^{2}=.05\right)$, and a significant SVO $\times$ Group Size Uncertainty interaction effect $\left(F(1,104)=7.01, p<.01, \eta^{2}=.06\right)$, as well as a significant main effect of Group Size Uncertainty $\left(F(1,104)=8.32, p<.01, \eta^{2}=.07\right)$, which was also qualified by the interaction.

To interpret the interaction effect, we tested whether the individual requests of proselfs differed from those of prosocials in each of the two Group Size (Un)certainty conditions. In accordance with Hypothesis 1, independent $t$ tests on the individual requests showed no significant difference between proselfs and prosocials under No Uncertainty $(M=95.15$ vs. 95.26, respectively) $(t(104)=0.02, p=.98)$. Under Uncertainty, however, prosocials requested significantly lower amounts of coins than proselfs $(M=100.25$ vs. 73.17 , respectively) $(t(104)=$ $2.55, p<.01)$. This latter finding corroborates Hypothesis 2.

Table 1. Study 1: Individual requests by social value orientation and group size uncertainty

\begin{tabular}{lrr}
\hline & & Group size uncertainty \\
\cline { 2 - 3 } Social value orientation & No & Yes \\
\hline Proselfs $(n=52)$ & $95.15(16.92)$ & $100.25(70.36)$ \\
Prosocials $(n=54)$ & $95.26(26.44)$ & $73.17(33.23)$ \\
\hline
\end{tabular}

Notes: Higher scores denote higher individual requests. Standard deviations are given in parentheses. 
Further, we also looked at the effect of group size uncertainty for proselfs and prosocials separately. To do so, we conducted two separate repeated measures ANOVAs (i.e. one for each SVO) with Group Size Uncertainty as the independent variable (i.e. No vs. Yes) and individual requests as the dependent variable. These analyses showed that the requests of proselfs did not differ significantly between the two (un) certainty conditions $(F(1,51)=.27, p=.61$, $\left.\eta^{2}=.01\right)$, whereas prosocials requested significantly lower amounts of coins in the Uncertainty condition than in the No Uncertainty condition $\left(F(1,53)=18.44, p<.001, \eta^{2}=.26\right){ }^{1}$

Adherence to equality To assess to what degree participants anchored their decisions on the equal division rule, we investigated to what extent their individual requests deviated from an equal share. In the Uncertainty condition we calculated this equal share by dividing the resource size (i.e. 500 coins) by the participants' own group size estimates. After that, we calculated the absolute difference between participants' individual requests and this equal share (for a similar procedure to assess adherence to coordination rules, see e.g. Van Dijk \& Wilke, 2000). A $2 \times 2$ ANOVA on the deviation scores only yielded a significant main effect of Group Size Uncertainty $\left(F(1,103)=8.12, p<.01, \eta^{2}=.07\right):$ participants' requests deviated significantly more from an equal share under Group Size Uncertainty $(M=18.05)$ than under No Group Size Uncertainty $(M=7.98)$. This finding further corroborates our reasoning that under group size uncertainty people anchor their decisions less strongly on the equal division rule than under group size certainty.

\section{Discussion}

The data of Study 1 corroborate our hypotheses by showing the predicted interaction between SVO and group size uncertainty. Whereas both prosocials and proselfs harvested about an equal share under certainty, under uncertainty prosocials harvested less for themselves than proselfs. Furthermore, our data showed that prosocials decreased their harvests under group size uncertainty, whereas for proselfs the mean harvests remained the same.

But why did prosocials display self-restraint under group size uncertainty? To answer this question, it may be useful to take a closer look at the motives that may drive prosocials' decisions. Prosocials can be characterized by two main motives: they strive toward (a) equality in outcomes and (b) maximized joint outcomes (see e.g. Van Lange, 1999). Therefore, it can be expected that these motives are important for them. However, the fact that these two motives are important for prosocials does not mean that these motives always explain their choice behavior. After all, although prosocials may be motivated to further both of these goals, they may not always be able to achieve them. For example, as we already argued in our introduction, equality is very difficult to apply under group size uncertainty (cf. De Kwaadsteniet, Van Dijk, Wit, De Cremer, \& De Rooij, 2007). Thus, even if prosocials are highly motivated to achieve equality, they may not be able to do so under group size uncertainty, not even by displaying self-restraint. Furthermore, the second motive that characterizes prosocials, namely maximizing joint outcomes, does not necessarily imply selfrestraint either. Thus, whether either one of these motives drives prosocials' self-restraint under group size uncertainty remains an empirical question. Therefore, we decided to investigate this issue in a second study, in which we explicitly measure these two motives.

\section{Study 2: The underlying motives of self-restraint}

First, we predict the same interaction as in Study 1, that under group size certainty both prosocials and proselfs will harvest about an equal share from the common resource (see Hypothesis 1), whereas under group size uncertainty prosocials will show more self-restraint than proselfs (see Hypothesis 2). Second, we will test whether prosocials' self-restraint may be explained by either one of the two motives we described above, namely (a) the 'Equality' motive and (b) the 'MaxJoint' motive. And finally, we expect to replicate the finding of 
Study 1 that under group size uncertainty people deviate more from equality than under group size certainty (Hypothesis 3 ).

\section{Method}

Participants and design Participants were 78 students at Leiden University (42 men and 36 women, mean age $=20.95$ years $)$ who volunteered for the study. The design of Study 2 was identical to that of Study 1. Again, first each participant's SVO was assessed (29 proselfs and 42 prosocials) and after that group size uncertainty was manipulated as a within-subjects factor. Accordingly, a 2 (SVO: Proselfs vs. Prosocials $) \times 2$ (Group Size Uncertainty: No vs. Yes) factorial design with repeated measures on the latter factor was used.

Procedure The procedure of Study 2 was similar to that of Study 1 . However, in this second study, after participants had made their individual requests, they were asked a number of questions to measure the motives underlying their harvesting decisions. Again, the two (un) certainty conditions were counterbalanced to check for order effects. Preliminary analyses revealed no significant order effects on any of the dependent variables (all $F \mathrm{~s}<1$ ). Before participants were presented with the social dilemmas, we again posed the same three practice questions as in Study 1. This time, $97 \%$ of all participants answered all three practice questions correctly. At the end of the experimental session, participants were paid 6 euros (i.e. approximately US\$8). They all agreed with this payment procedure.

Dependent measures As in Study 1, in both (un)certainty conditions participants requested a number of coins from the common resource. After that, in each (un) certainty condition, two questions were posed about the motives that might have driven their decisions: (a) participants were asked to what extent they wanted their group to earn as much as possible (the 'MaxJoint' motive), and (b) they were asked to what extent they wanted the common resource to be distributed equally among the group members (the 'Equality' motive). ${ }^{2}$ Both questions were answered on 7-point Likert scales $(1=$ not at all; 7 = very much so) .

\section{Results}

Manipulation check In each of the two (un)certainty conditions, we asked participants to indicate how uncertain they were about the size of the group ( 1 = very certain; 7 = very uncertain). A $2 \times 2$ ANOVA on this measure only yielded a highly significant main effect of Group Size Uncertainty $(F(1,69)=595.76, p<.0001$, $\left.\eta^{2}=.90\right)$. As expected, participants were more uncertain about their estimates under Group Size Uncertainty $(M=6.32)$ than under No Group Size Uncertainty $(M=1.44)$. These results show that we were successful in manipulating group size uncertainty.

Individual requests As in Study 1, a 2 × 2 ANOVA on participants' individual requests yielded a significant $\mathrm{SVO} \times$ Group Size Uncertainty interaction effect $\left(F(1,69)=5.13, p<.05, \eta^{2}=.07\right)$, indicating that whereas prosocials' and proselfs' requests did not differ significantly under No Uncertainty ( $M=97.50$ vs. 105.17 , respectively) $(t(69)=1.21, p=.23)$, prosocials requested significantly less than proselfs under Uncertainty $(M=84.95$ vs. 122.69 , respectively $)(t(69)=2.87$, $p<.01){ }^{3,4}$ In other words, as we expected, under group size uncertainty prosocials showed more self-restraint than proselfs.

MaxJoint and equality Two separate $2 \times 2$ ANOVAs on (a) the 'MaxJoint' motive and (b) the 'Equality' motive both yielded significant main effects of Group Size Uncertainty (both $F_{\mathrm{s}}>4.40$, both $p s<.05)$, and significant main effects of SVO (both $F \mathrm{~s}>7.50$, both $p \mathrm{~s}<.01$ ). These analyses indicated that under No Uncertainty participants were more motivated to achieve these two goals than under Uncertainty, and that prosocials were more motivated to achieve these goals than proselfs. This latter finding is in line with the definition of prosocials as finding both motives important. See Table 2 for the means involved in these analyses.

Which motive underlies self-restraint? The main goal of Study 2 was to investigate which 
Table 2. Study 2: The 'MaxJoint' and 'Equality' motives by social value orientation and group size uncertainty

\begin{tabular}{|c|c|c|c|c|}
\hline \multirow[b]{3}{*}{ Social value orientation } & \multicolumn{4}{|c|}{ Group size uncertainty } \\
\hline & \multicolumn{2}{|c|}{ No } & \multicolumn{2}{|c|}{ Yes } \\
\hline & MaxJoint & Equality & MaxJoint & Equality \\
\hline Proselfs $(n=52)$ & $\begin{array}{c}4.55 \\
(1.76)\end{array}$ & $\begin{array}{c}4.93 \\
(2.05)\end{array}$ & $\begin{array}{c}3.79 \\
(1.74)\end{array}$ & $\begin{array}{c}4.55 \\
(2.06)\end{array}$ \\
\hline Prosocials $(n=54)$ & $\begin{array}{c}5.43 \\
(1.64)\end{array}$ & $\begin{array}{c}6.00 \\
(1.34)\end{array}$ & $\begin{array}{c}5.17 \\
(1.62)\end{array}$ & $\begin{array}{c}5.40 \\
(1.59)\end{array}$ \\
\hline
\end{tabular}

Notes: Higher scores denote stronger motives. Standard deviations are given in parentheses.

motive may have driven prosocials' self-restraint under group size uncertainty. To investigate this, we tested whether the effect of SVO on individual requests under group size uncertainty (i.e. that prosocials show more self-restraint than proselfs) was mediated by the two motives we mentioned above. This mediation analysis (see Baron \& Kenny, 1986) showed that the effect of SVO on individual requests was fully mediated by the 'MaxJoint' motive (Sobel test value $=-2.32, p<.05$ ), but not by the 'Equality' motive. Although we would like to note that caution is warranted in interpreting such mediation analyses, these findings seem to imply that prosocials' self-restraint under group size uncertainty may be explained by their motivation to maximize their group's outcomes.

Adherence to equality As in Study 1, we also investigated to what degree participants anchored their decisions on the equal division rule in the two Group Size (Un)certainty conditions. Again, using their own group size estimates, we calculated to what extent their individual requests deviated from an equal share. As predicted, a $2 \times 2$ ANOVA on the (absolute) deviation scores yielded a significant main effect of Group Size Uncertainty $(F(1,68)=3.11$, $p<.05, \eta^{2}=.04$, one-sided). This main effect indicated that participants' requests deviated significantly more from an equal share under Group Size Uncertainty $(M=16.86)$ than under No Group Size Uncertainty $(M=10.64)$. This finding corroborates Hypothesis 3, that under group size uncertainty people anchor their decisions less strongly on the equal division rule than under certainty.

\section{Discussion}

The data of Study 2 again showed the predicted interaction between SVO and group size uncertainty. Whereas both prosocials and proselfs harvested about an equal share under group size certainty, under group size uncertainty prosocials showed more self-restraint than proselfs. Furthermore, although our data showed that the Equality and MaxJoint motives are both important motives for prosocials (see Table 2), our mediation analyses suggested that the selfrestraint of prosocials (that was observed under group size uncertainty) can be understood by their motivation to maximize joint outcomes. Finally, we again showed that under group size uncertainty people deviate more from equality than under group size certainty.

\section{General discussion}

In the present article, we reported two experimental studies that investigated the influence of group size uncertainty and SVO in social dilemmas. Both studies corroborate our idea that group size uncertainty has important consequences for how people tacitly coordinate their behavior. Under group size certainty, people can efficiently coordinate their behavior by applying the equal division rule. By contrast, under group size uncertainty tacit coordination is hampered because the task environment does not provide people with the salient cue to apply the equal division rule. In that case, people rely on internal cues (i.e. their SVO) to determine their harvesting decisions. Additionally, we demonstrated that, in contrast to earlier findings on resource size uncertainty (e.g. Budescu 
et al., 1990; Gustafsson et al., 1999), group size uncertainty does not necessarily induce overharvesting.

Thus, on the one hand our results show that group size uncertainty hampers efficient coordination. At the same time, however, our results corroborate and extend Au and Ngai's (2003) findings by showing that group size uncertainty is not necessarily detrimental to collective interests, even when people make their harvesting decisions simultaneously (and they cannot know their fellow group members' decisions). Interestingly, whereas earlier research has shown that uncertainty about the size of the common resource leads to non-cooperative behavior, the present findings indicate that uncertainty about the size of the group may even induce some people (i.e. prosocials) to show self-restraint. However, this finding raised the question as to why exactly group size uncertainty induced prosocials to show self-restraint. Was their self-restraint motivated by equality or by the motive to maximize joint outcomes? The findings of Study 2 showed that, although both motives are important for prosocials, their selfrestraint may be explained by their motivation to maximize joint outcomes. These results indicate that the motive to maximize joint outcomes may have driven the self-restraint that we observed under group size uncertainty and perhaps also the self-restraint that $\mathrm{Au}$ and Ngai observed in their study.

Our data thus suggest that prosocials may have reasoned that under group size uncertainty self-restraint is beneficial to the collective. But is self-restraint really a good means to maximize the group's outcomes? A plausible answer to this question can be found in Au and Ngai's paper (2003). In an appendix to their paper, they presented a calculative analysis that showed that in order to maximize group earnings, individual requests should decrease as the size of the group becomes more uncertain. More specifically, the expected utility for the group and its members is largest when all group members determine their harvesting decisions based on the largest possible group size. In other words, if group members want to maximize their group's payoffs, it is best to coordinate their individual harvests by dividing the common resource by the largest group size possible (i.e. in our singletrail resource dilemma they should each harvest $500 / 8=$ about 60 coins). Thus, under group size uncertainty self-restraint indeed seems to be beneficial to the collective interest.

As we already noted in the introduction to this article, the present research was strongly based on Au and Ngai's (2003) paper on group size uncertainty. Our first goal was to see whether their findings would generalize to a resource dilemma with a simultaneous protocol. Therefore, we decided to use a social dilemma paradigm that closely resembled the one that was used by Au and Ngai. In this paradigm, participants have only one chance to harvest any amount of coins from the common resource. However, if the collective harvest exceeds the amount available in the common resource, no one receives anything (see also e.g. Budescu et al., 1990; De Kwaadsteniet et al., 2006; Gustafsson et al., 1999, for similar paradigms). Although this single-trial resource dilemma is often referred to as a social dilemma game, it also has some characteristics of a coordination game (see De Vries \& Wilke, 1992). Therefore, the question remains as to whether the present results would generalize to other social dilemma paradigms. For instance, would people still show so much self-restraint if the consequences of over-harvesting were in the future, such as in a multiple-trial social dilemma with group size uncertainty? And does a multiple-trial dilemma-in which there is no clear absolute maximum total request-constitute a weaker situation than the single-trial dilemma we used in the present research? To investigate the generalizability of the present results, it is important to address these and other questions in future research.

It is also worthwhile to acknowledge the fact that the data of both studies provide firm support for the suggestion that Snyder and Ickes' (1985) weak-strong distinction is highly applicable to social dilemma situations (see also De Kwaadsteniet et al., 2006; Roch \& Samuelson, 1997; Van Lange, 1997). In the present research, we showed that when the task environment of a social dilemma provides a salient cue to guide 
behavior, people will base their decisions on that cue (e.g. the equal division rule under group size certainty), whereas they will base their decisions on their own disposition when the task environment does not provide such a cue (e.g. their SVO under group size uncertainty). These findings thus clearly show that Snyder and Ickes' framework (1985) on strong versus weak situations can be fruitfully used to explain and predict choice behavior in social dilemmas, and we therefore believe that future research may greatly benefit from applying this framework to social dilemmas.

To summarize, the present studies have generated a number of interesting findings. First, we showed that group size uncertainty-as opposed to resource size uncertainty-does not induce general over-harvesting and that this type of uncertainty is not necessarily detrimental to collective interests. After all, group size uncertainty induces prosocials to show selfrestraint under uncertainty. Second, we showed that group size uncertainty hampers efficient coordination, inducing people to base their decisions on internal cues (i.e. their SVO) instead of external ones (i.e. the equal division rule), which corroborates the suggestion that Snyder and Ickes' (1985) weak-strong distinction can fruitfully be applied to social dilemmas. And third, we showed that prosocials' self-restraint under group size uncertainty may be explained by their motive to maximize their group's outcomes. Taken together, by investigating the topic of group size (un) certainty in social dilemmas and relating this topic to tacit coordination and SVO, the present studies have generated a number of new insights into this largely unexplored type of environmental uncertainty.

\section{Notes}

1. These analyses were also done on proself and prosocials' transformed requests (i.e. transformed by applying square root transformations), which yielded the same results.

2. It may be interesting to note that we also measured to what extent participants were motivated to maximize their own outcomes (i.e. the 'MaxOwn' motive). As expected, we found that proselfs were more motivated by this motive than prosocials and that this motive was positively correlated with participants' harvests. However, a mediation analysis showed that this motive did not mediate the effect of SVO on harvests under group size uncertainty.

3. As in Study 1, we also conducted these analyses after applying a square root transformation. These analyses yielded similar results.

4. It should be noted that in contrast to Study 1 , in Study 2 we did not find a main effect of Group Size Uncertainty on individual requests $\left(F(1,69)=0.14, p=71, \eta^{2}=.002\right)$. The mean requests seemed to be almost identical in the two (un) certainty conditions $\left(M_{\text {No Uncertainty }}=\right.$ 100.63 vs. $\left.M_{\text {Uncertainty }}=100.37\right)$. This difference between the results of the two studies can be explained by the fact that whereas in Study 1 the requests of proselfs appeared to be unaffected by group size uncertainty, in Study 2 their mean requests increased slightly under uncertainty (from 105.17 coins to 122.69 coins). However, as in Study 1, prosocials still decreased their mean requests under group size uncertainty (from 97.50 coins to 84.95 coins) and they again showed self-restraint under such uncertainty.

\section{References}

Allison, S. T., \& Messick, D. M. (1990). Social decision heuristics in the use of shared resources. Journal of Behavioral Decision Making, 3, 195-204.

Au, W. T., \& Ngai, M. Y. (2003). Effects of group size uncertainty and protocol of play in a common pool resource dilemma. Group Processes E Intergroup Relations, 6, 265-283.

Baron, R. M., \& Kenny, D. A. (1986). The moderator-mediator variable distinction in social psychological research: Conceptual, strategic, and statistical considerations. Journal of Personality and Social Psychology, 51, 1173-1182.

Budescu, D. V., Rapoport, A., \& Suleiman, R. (1990). Resource dilemmas with environmental uncertainty and asymmetric players. European Journal of Social Psychology, 20, 475-487.

De Kwaadsteniet, E. W., Van Dijk, E., Wit, A., \& De Cremer, D. (2006). Social dilemmas as strong versus weak situations: Social value orientations and tacit coordination under resource size uncertainty. Journal of Experimental Social Psychology, 42, 509-516.

De Kwaadsteniet, E. W., Van Dijk, E., Wit, A., De Cremer, D., \& De Rooij, M. (2007). Justifying decisions in social dilemmas: Justification 
pressures and tacit coordination under environmental uncertainty. Personality and Social Psychology Bulletin, 33, 1648-1660.

De Vries, S., \& Wilke, H. A. M. (1992). Constrained egoism and resource management under uncertainty. In W. B. G. Liebrand \& D. M. Messick (Eds.), Social dilemmas: Theoretical issues and research findings (pp. 81-100). Oxford, UK: Pergamon Press.

Eisenberger, R., Kuhlman, D. M., \& Cotterell, N. (1992). Effects of social values, effort training, and goal structure on task persistence. Journal of Research in Personality, 26, 258-272.

Gustafsson, M., Biel, A., \& Gärling, T. (1999). Over-harvesting of resources of unknown size. Acta Psychologica, 103, 47-64.

Hine, D. V., \& Gifford, R. (1996). Individual restraint and group efficiency in commons dilemmas: The effects of two types of environmental uncertainty. Journal of Applied Social Psychology, 26, 993-1009.

Komorita, S. S., \& Parks, C. D. (1995). Interpersonal relations: Mixed-motive interaction. Annual Review of Psychology, 46, 183-207.

Kopelman, S., Weber, J. M., \& Messick, D. M. (2002). Factors influencing cooperation in commons dilemmas: A review of experimental psychological research. In E. Ostrom, T. Dietz, N. Dolsak, P. C. Stern, S. Stonich, \& E. U. Weber (Eds.), The drama of the commons. Washington, DC: National Academy Press.

Kramer, R., McClintock, C. G., \& Messick, D. M. (1986). Social values and cooperative response to a simulated resource conservation crisis. Journal of Personality, 54, 101-117.

Liebrand, W. B. G., \& Messick, D. M. (1996). Social dilemmas: Individual, collective, and dynamic perspectives. In W. B. G. Liebrand \& D. M. Messick (Eds.), Frontiers in social dilemmas research (pp. 1-9). Berlin: Springer Verlag.

Liebrand, W. B. G., \& Van Run, G. J. (1985). The effects of social motives on behavior in social dilemmas in two cultures. Journal of Experimental Social Psychology, 22, 203-215.

McClintock, C. G., \& Liebrand, W. B. G. (1988). Role of interdependence structure, individual value orientation, and another's strategy in social decision making: A transformational analysis. Journal of Personality and Social Psychology, 55, 396-409.

Messick, D. M., Allison, S. T., \& Samuelson, C. D. (1988). Framing and communication effects on group members' responses to environmental and social uncertainty. In S. Maital (Ed.), Applied behavioral economics (Vol. 2, pp. 677-700). New York: New York University Press.

Messick, D. M., \& McClintock, C. G. (1968). Motivational bases of choice in experimental games. Journal of Experimental Social Psychology, 4, 1-25.

Ostrom, E. (1990). Governing the commons: The evolution of institutions for collective action. Cambridge, UK: Cambridge University Press.

Parks, C. D. (1994). The predictive ability of social values in resource dilemmas and public good games. Personality and Social Psychology Bulletin, 20, 431-438.

Platow, M. J. (1994). An evaluation of the social desirability of prosocial self-other allocation choices. Journal of Social Psychology, 134, 61-68.

Roch, S. G., \& Samuelson, C. D. (1997). Effects of environmental uncertainty and social value orientation in resource dilemmas. Organizational Behavior and Human Decision Processes, 70, 221-235.

Schelling, T. C. (1980). The strategy of conflict, 1980 edition. Cambridge, MA: Harvard University.

Snyder, M., \& Ickes, W. (1985). Personality and social behavior. In G. Lindzey \& E. A. Aronson (Eds.), Handbook of social psychology: Vol. 2. Special fields and applications (pp. 883-925). New York: Random House.

Takigawa, T., \& Messick, D. M. (1993). Group size uncertainty in shared resource use. Japanese Psychological Research, 35, 193-203.

Van Dijk, E., \& De Cremer, D. (2006). Tacit coordination and social dilemmas: On the importance of self-interest and fairness. In D. De Cremer, M. Zeelenberg, \& J. K. Murnighan (Eds.), Social psychology and economics (pp. 141-154). Mahwah, NJ: Psychology Press.

Van Dijk, E., \& Wilke, H. (1996). Tacit coordination and fairness judgments in social dilemmas. In W. B. G. Liebrand \& D. M. Messick (Eds.), Frontiers in social dilemmas research (pp. 117-134). Berlin: Springer-Verlag.

Van Dijk, E., \& Wilke, H. (2000). Decision-induced focusing in social dilemmas: Give-some, keep-some, take-some, and leave-some dilemmas. Journal of Personality and Social Psychology, 78, 92-104.

Van Dijk, E., Wit, A., Wilke, H., \& Budescu, D. V. (2004). What we know (and do not know) about the effects of uncertainty on behavior in social 
dilemmas. In R. Suleiman, D. Budescu, I. Fisher, \& D. Messick (Eds.), Contemporary psychological research on social dilemmas (pp. 315-331).

Cambridge, UK: Cambridge University Press.

Van Lange, P. A. M. (1997). Movement in social orientations: A commentary on Kelley. European Journal of Social Psychology, 27, 423-432.

Van Lange, P. A. M. (1999). The pursuit of joint outcomes and equality in outcomes: An integrative model of social value orientation. Journal of Personality and Social Psychology, 77, 337-349.

Van Lange, P. A. M., De Bruin, E. M. N., Otten, W., \& Joireman, J. A. (1997). Development of prosocial, individualistic, and competitive orientations: Theory and preliminary evidence. Journal of Personality and Social Psychology, 73, 733-746.

Van Lange, P. A. M., \& Kuhlman, D. M. (1994). Social value orientations and impressions of partner's honesty and intelligence: A test of the might versus morality effect. Journal of Personality and Social Psychology, 67, 126-141.

Van Lange, P. A. M., \& Liebrand, W. B. (1991). Social value orientation and intelligence: A test of the Goal Prescribes Rationality Principle. European Journal of Social Psychology, 21, 273-292.

Paper received 19 May 2006; revised version accepted 31 October 2007.

\section{Biographical notes}

ERIK W. DE KWAADSTENIET is an assistant professor of social and organizational psychology in the department of social and organizational psychology, Leiden University. His research focuses on uncertainty in social dilemmas.

ERIC VAN DIJK is a full professor of social and organizational psychology at Leiden University. His research focuses on social decision making, and in particular on social dilemmas and bargaining.

ARJAAN WIT is an assistant professor of social and organizational psychology at Leiden University. His research focuses on social dilemmas, cooperation and leadership.

DAVID DE CREMER is a full professor of social and organizational psychology at the Center of Justice and Social Decision Making, Tilburg University. His research focuses on justice, self/identity, and social decision-making. 